\title{
La triple secuencia multiplataforma y la audiencia social en COPE. La narración distribuida de contenidos en la antena, la web, redes socialesy alertas a teléfono móvil durante el Día de la Radio en 'Herrera en COPE'
}

\author{
Andoni Orrantia Herrán \\ Universidad del País Vasco-Euskal Herriko Unibertsitatea (UPV-EHU) \\ aorrantiah@gmail.com \\ https://twitter.com/aorrantiah
}

\begin{abstract}
The triple cross-platform sequence and the social audience in COPE. The distributed narration of contents in the antenna, the web, social networks and alerts to mobile phone during the Day of the Radio in 'Herrera in COPE'
\end{abstract}

\begin{abstract}
RESUMEN
Los nuevos dispositivos móviles han cambiado la forma de acceder a los contenidos, han creado nuevos hábitos de consumo y han hecho posible estar conectado a cualquier hora.

En este contexto, la radio digital debe esforzarse a diario por ofrecer nuevos modelos de comunicación. La radio debe ser capaz de sacar el máximo partido a la triple secuencia multiplataforma, objeto de estudio del caso de 'Herrera en

COPE'. En esa secuencia, la antena, la web, las redes y las alertas a teléfono móvil tienen su ritmo y su tiempo de distribución y cada contenido su formato. Esta investigación fija su objetivo mediante técnicas cualitativas y cuantitativas en comprobar si la existencia de una estrategia que pasa por una redacción integrada, mejora la creación de contenidos durante un hecho previsto como el Día de la Radio, su posterior distribución en distintas plataformas y la interacción con

las audiencias. Una de las principales conclusiones refleja cómo la promoción cruzada de la marca COPE a través de la antena, la web, la app y las redes fidelizó al público. El número de usuarios concurrentes aumentó un $8 \%$ y el de
\end{abstract} nuevos un $65 \%$.

PALABRAS CLAVE

Redacción integrada, Teléfono móvil, Red social, Audiencia, Producción transmedia, Distribución

\section{ABSTRACT}

The new mobile devices have changed the way they access content, have created new consumption habits and have made it possible to be connected at any time. In this context, digital radio should strive daily to offer new communication models. The radio must be able to make the most of the triple multiplatform sequence, object of study of the case of 'Herrera en COPE'. In that sequence, the antenna, the web, the networks and the alerts to mobile phone have their rhythm and their distribution time and each content their format. This research sets its objective through qualitative and quantitative techniques to check whether the existence of a strategy that goes through an integrated wording, improves the creation of content during a planned event such as Radio Day, its subsequent distribution on different platforms and interaction with the audiences. One of the main conclusions reflects how the cross-promotion of the COPE brand through the antenna, the web, the app and the networks loyalized the public. The number of concurrent users increased by $8 \%$ and the number of new ones by $65 \%$.

\section{KEYWORDS}

Converged newsrooms, Mobile phone, Social network, Audience, Transmedia production, Distribution la Radio en 'Herrera en COPE'. Hipertext.net, (16), 43-50. DOI:10.31009/hipertext.net.2018.i16.08 


\section{Introducción}

Los nuevos dispositivos móviles han cambiado la forma de acceder a los contenidos y han hecho posible estar conectado a cualquier hora. Sólo en 2010, los smartphones suponían el $37 \%$ de los teléfonos móviles que se utilizaban en España, frente al 28\% de EEUU, según un estudio realizado por Nielsen. En la actualidad, los smartphones representan más del $81 \%$ de los teléfonos en España. Hemos pasado de un modelo basado en la posesión del contenido a otro en el que la secuencia no acaba en el acceso al mismo sino en comentarlo o compartirlo. Las redes representan el nuevo motor de comunicación y de convocatoria ante hechos programados o imprevistos. Con ellas, se ha dado la transición del qué estás haciendo al qué está pasando. Hace cinco años, apenas el 28\% de los internautas españoles las usaba a diario, ahora es ya el 86\%. Facebook consolida su posición hegemónica (es utilizada por el 91\% de los usuarios); seguida todavía a gran distancia de Twitter (50\%). Así se desprende del Estudio anual de Redes Sociales 2017 elaborado por IAB Spain.

En este contexto, la radio digital debe esforzarse a diario por ofrecer nuevos modelos de comunicación. La radio debe ser capaz de sacar el máximo partido a lo que centra esta investigación: la triple secuencia multiplataforma, donde cada soporte tiene su ritmo y tiempo de distribución y cada contenido su formato. La radio deberá volcar esfuerzos en la producción transmedia como modo de pensar la creación de contenidos de acuerdo con los nuevos hábitos de consumo e interacción de las audiencias.

\section{La narración distribuida del contenido. La dimensión comunicativa de la redacción integrada}

La redacción integrada en los medios ha abierto en los últimos diez años nuevas posibilidades a los lenguajes periodísticos. Por ejemplo, hasta la llegada de la televisión e Internet no existía un soporte que permitiera difundir mensajes en los que se combinaran códigos textuales y audiovisuales. Además, como la redacción integrada en su ámbito empresarial implica que múltiples áreas combinen sus recursos para alcanzar a una mayor variedad de usuarios; la dimensión comunicativa no centra sólo su potencial en los elementos comunicativos sino también en las personas que reciben la información y en sus hábitos de consumo.

La aparición de nuevos soportes está fragmentando el tiempo que dedicamos a los contenidos. Lo vaticinaba Herbert Simon sin conocer las nuevas plataformas: "lo que consume la información es la atención de sus receptores" (Simon, 1971: 40). Y es hoy, entre tanto soporte y contenido; donde se hace necesario asignar eficientemente esa atención. Nieto lo dejó por escrito: el mercado de la información debe ser entendido como mercado del tiempo (Nieto, 2001: 134-138).
Los medios, según Goldhaber (1997), compiten en una economía de la atención. Los medios batallan en un escenario en el que deben responder a cuestiones como ¿qué me ofreces de diferente para leerte, escucharte o verte?. Hasta ahora, los periodistas han trabajado con las $5 \mathrm{~W}$ y respondiendo a cinco preguntas aportaban la información del hecho. Los periodistas tenían esa exclusividad. Ahora, se mueven de manera urgente por la demanda que el usuario le hace de lo que bautizamos como las 3W (qué está pasando, cuándo me lo ofreces y en qué soporte). Se ha pasado del interés público al interés del público.

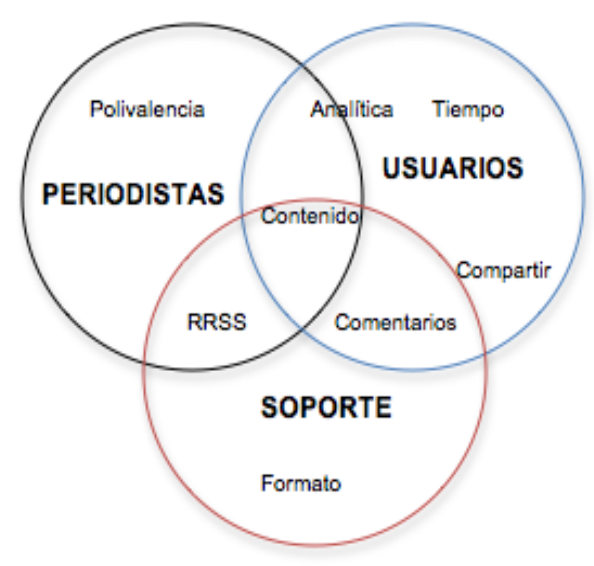

Figura 1. Del interés público al interés del público. Elaboración propia.

El usuario y el periodista se mueven en paralelo en tres círculos que convergen. En uno, el profesional del medio, con un perfil polivalente a la hora de producir y distribuir el contenido habiendo perdido la exclusividad en la construcción de la información entendida como contenido (Tous Rovirosa, et al. 2015; Cerezo, 2016). Enfrente, el usuario como fuente, lector y distribuidor. La idea de que el público va al medio caducó por la naturaleza migrante de las audiencias enunciada por Jenkins (2008). Ahora, el éxito de los medios pasa por acceder a su teléfono móvil. Como se detallará más adelante en el caso de COPE, un hashtag crea un universo informativo. En opinión de Hermida, se configura "un sistema de comunicación e información amplio, asincrónico, ligero y siempre disponible que habilita nuevas formas de interacción alrededor de los contenidos publicados" (Hermida, 2010: 2).

Junto al profesional y el usuario, el soporte se encarga de cerrar esa confluencia de circunferencias. Sostiene Cabrera (2012) que el tiempo real sustituye a la periodicidad de los medios tradicionales y eso es crucial en el consumo de contenidos. Un escenario que Fogel y Patiño definían como la "fragmentación de las audiencias" (Fogel y Patiño, 2007: 24). Las potencialidades de las redes exigen a los medios un 
esfuerzo por desarrollar nuevos formatos que aprovechen esas utilidades. Es lo que Armentia et al. describen como la apertura "a nuevas formas de hacer periodismo" (2000: 14,191 y 201). La multimedialidad a la que se refieren López et al. cuando hablan de "una integración en una misma unidad discursiva de información varios tipos; el hipertexto, la vinculación de varios documentos a través de palabras o frases comunes; la interactividad, con la que el receptor deja de ser un elemento pasivo para poder tomar decisiones y configurar, dentro de unos límites, su propio mensaje; y la actualización constante" (López, et al., 2010: 10).

Surgen nuevos formatos para nuevos hábitos de consumo. Frente al texto, se erige la viewradio. En opinión de De Biase, "Internet no debe suponer lo que somos, sino lo que podemos llegar a ser" (De Biase, 2011: 34) con cada vez mayores dosis de interactividad. Hace 20 años los usuarios consumían los medios a través de dos únicos sentidos: la vista y el oído. En opinión de Salaverría, "la llegada Internet supuso un avance en la conformación de un nuevo lenguaje periodístico multimedia" (Salaverría, 2002: 2). Entre otras cosas, debido a que a las potencialidades sensoriales que ofrecían los tres medios tradicionales (prensa, radio y televisión) se han sumado nuevas posibilidades. Para García Avilés (2002) con el tiempo, la Red se ha ido consolidando como un medio muy eficaz para suministrar información audiovisual. Se ha pasado de ofrecer en una primera etapa formatos muy primitivos a disponer en la actualidad todos los medios de todos los recursos. En el caso de COPE, objeto de esta investigación y como apunta en una entrevista realizada en la redacción de Madrid el 13 de marzo de 2017, Cele Díaz, desarrollador de nuevos proyectos, tráfico digital y usuarios en cope.es, "la noticia es el elemento fundamental y debe ser lo más completa posible con texto, audio, fotos o vídeo para retener al lector el mayor tiempo posible."

Para Chávez "en un primer momento la radio se incorporó a Internet sólo para dejar constancia de su existencia, reforzar su imagen y difundir las parrillas de programación" (Chávez, 2013: 30). No obstante, en opinión de Merayo "el soporte no tenía que ser visto como competencia sino como la posibilidad de ofrecer nuevos servicios" (Merayo, 2001: 209). A medida que pasan los años, las emisoras van incorporando en la red nuevos mecanismos para la distribución de sus contenidos en línea. La ciberradio es una radio para un oyente social y móvil. Porque como sostienen Piñeiro-Otero y Videla "la radio online, neorradio, radio virtual, Internet only, iRadio, ciberradio o webradio perfila nuevos usos, diversas formas de producción y distribución de contenidos" (Piñeiro-Otero y Videla, 2013: 69). Para Rivadeneyra, como analizamos con COPE, "han implicado la aparición de un nuevo rol de oyente-usuario" (Rivadeneyra, 2008: 240).

\section{La audiencia social y la triple secuencia multiplataforma}

Según Peñafiel, "la radio digital debe esforzarse por ofrecer un nuevo modelo de comunicación, con la renovación de lenguajes y formatos" (Peñafiel, 2004: 17). Con Internet, ya no está sujeta a una programación predeterminada donde los contenidos tienen un horario fijo y la audiencia debe adaptarse a ellos. Internet, el podcast, la irrupción de los teléfonos móviles, de las apps, las redes y las alertas rompen con estas limitaciones y crean lo que denominamos triple secuencia multiplataforma en la distribución de contenidos.

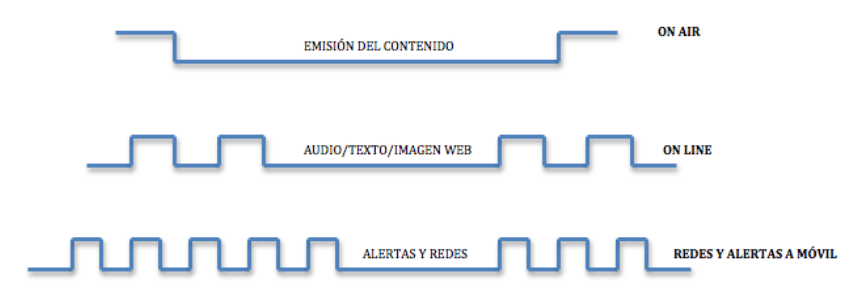

Figura 2. Triple secuencia multiplataforma. Elaboración propia.

En esta triple secuencia, cada soporte tiene su ritmo de distribución del contenido. Así, mientras que la antena tiene una linealidad previsible (empieza y acaba con el directo), la escucha por Internet viene precedida de un aviso recordatorio antes de la emisión, de la difusión on line de ese contenido (con audio y/o con video). En el caso de las entrevistas políticas por ejemplo, del colgado inmediato de una foto, texto y audio y una vez finalizado el programa, del colgado completo del mismo. En el caso de las redes y de las alertas, Pilar Abad, editora de redes de COPE sostiene en una entrevista realizada en la redacción de Madrid el 13 de marzo de 2017 que "la actividad es total ya que previamente se lanzan mensajes que sirvan de anzuelo para redireccionar al usuario de Twitter, Facebook o de la app a la antena; durante la emisión se van emitiendo titulares (texto solo o acompañado de fotos) a 140 caracteres de lo que en el programa se está diciendo y una vez finalizado el mismo, se difunde el audio completo o también fragmentos de vídeo en Twitter y Facebook".

Para Castells et al., Internet, el podcast, la irrupción de los teléfonos móviles, de las apps y las redes suponen "nuevas formas de expansión de la radiofonía on line" (Castells, et al., 2006). En el caso de las redes, Meso considera que "el aspecto socio-interactivo adoptado por las comunicaciones digitalizadas promueven la puesta en marcha de un modelo de diálogo horizontal y circular con el público lejos del modelo jerárquico y unidireccional propio de los medios convencionales" (Meso, 2013: 68). Entrevistado en la redacción de COPE en Madrid, Javier Visiers, Director de Programación, argumenta que 
"plataformas como Twitter o Facebook son un medio de comunicación más con un público determinado". En este sentido, en el caso de COPE el oyente digital difiere del analógico. El 77,6\% de los usuarios de cope.es tiene entre 25 y 54 años mientras que la edad media del oyente es de 53. Son hombres y viven en Madrid, Barcelona y Sevilla. Más de la mitad de los usuarios es fiel a cope.es. El 78\% del tráfico procede de teléfono móvil según datos de octubre de 2017 de comScore. En cuanto a su audiencia social, según estudios internos de COPE, siete de cada diez oyentes están presentes en Facebook.

Con este escenario de fondo, Orihuela (2003) considera que los medios entienden como centro de su negocio el contenido. En este contexto, la dimensión comunicativa de una redacción integrada confiere a la marca informativa un valor que hace aumentar la calidad y el prestigio de los contenidos difundidos a través de sus diferentes lenguajes.

Después de lo expuesto, se observa que la triple secuencia multiplataforma llevada a cabo dentro de una redacción integrada y ante un acontecimiento programado como el que se analiza, reclama esencialmente tres desafíos: planificación, innovación y formación. La planificación resulta necesaria en el plano editorial y no sólo en el administrativo. La innovación apunta a los aspectos tecnológicos pero también a los comunicativos, como se ha visto en este epígrafe. Para Visiers, "la tecnología es un habilitador. El consumo es el que está habilitado por esa tecnología". Y la formación fomenta el uso profesional de los recursos digitales por parte de los periodistas al tiempo que les invita a experimentar con nuevas narrativas interactivas de presentar la información.

\section{Hipótesis y objetivos de la investigación}

En la presente investigación, partimos de la importancia de comprender las transformaciones que ha experimentado también la radio a partir de su presencia en Internet. Así, será el podcast en un primer momento y después, las apps, las redes y las alertas quienes abran paso a una audiencia fragmentada, capaz de convertirse en su propio programador de contenidos. Para Cebrián Herreros se produce "la ruptura de la concepción emisión-recepción o de la sincronía-simultaneidad por la asincronía-diferido" (Cebrián Herreros, 2008: 35).

Esta investigación busca analizar ante un acontecimiento previsto, los modelos de producción y distribución de los contenidos informativos en COPE y en 'Herrera en COPE', teniendo en cuenta que:

- Según la 3a Oleada del EGM 2015 'Herrera en COPE' dejaba una fotografía sin precedentes en la radio y conseguía un millón de oyentes más tras su salida de Onda Cero

- Según la 3a Oleada del EGM 2017, COPE es la segunda emisora de radio más escuchada en España con 2.824.000 oyentes y 'Herrera en COPE' obtiene su récord de audien- cia con 2.034.000.

Con estos datos, el estudio de este caso se fija como hipótesis principal:

- La existencia de una estrategia que pasa por una redacción integrada mejora la creación de los contenidos en COPE durante un hecho previsto (el Día de la Radio, el 13 de febrero de 2017) y su posterior distribución en la antena, la web, Twitter, Facebook y alertas a teléfono móvil.

El análisis de la redacción integrada se realiza desde una perspectiva múltiple que se engloba en un objetivo principal:

- Comprobar presencialmente las metodologías de trabajo de los distintos equipos antes del Día de la Radio y durante el mismo y detectar in situ (en esos dos escenarios) si existen o no sinergias entre los equipos y en caso afirmativo, analizar de qué tipo, qué instrumentos las posibilitan y qué contenido y en qué formato se distribuye.

\section{Metodología}

Debemos indicar que se trata del estudio de un caso único: 'Herrera en COPE'. Durante el diseño metodológico partimos del conocimiento de que nos enfrentamos a un objeto de análisis en constante evolución y en consecuencia, exige la utilización de distintos métodos que nos permitan responder a los objetivos planteados.

Tal y como sostienen Wimmer y Dominick "para realizar una investigación científica, es decir, una averiguación sistemática controlada, práctica y crítica sobre proposiciones hipotéticas acerca de la supuesta relación entre los fenómenos observados, se puede optar por un enfoque cualitativo o cuantitativo" (Wimmer y Dominick, 1996: 8). Ha sido el caso de esta investigación. Con las técnicas cuantitativas, para Bruhn "el objeto y medio de análisis es un número" (Bruhn, 1993: 14). En este sentido, se han analizado los contenidos creados a raíz del espacio emitido en antena (noticias, áudios, vídeos, tweets, post y alertas) así como el impacto generado en su web y en redes.

La investigación cualitativa nos ha sido útil puesto que uno de los objetivos era observar el trabajo en la redacción de COPE en Madrid y precisamente este método ayuda a percibir un comportamiento en un ambiente real. Tras valorar su idoneidad para desarrollar la presente investigación, se decidió optar por dos fases:

- Entrevistas personales en la sede central del medio al Director de Programación así como a una editora de redes y a un responsable de cope.es

- Observación in situ de la metodologia de trabajo de la redacción integrada un día normal y la mañana del 13 de febrero de 2017. Para delimitar los contenidos que se que- 
rían analizar, se acotó el análisis al tramo que comprendía en antena de 9 a 10:05h.

\subsection{Análisis del medio y de los contenidos publicados}

En la distribución convencional de su señal, la cadena propiedad de la Conferencia Episcopal, concentra cada día según la 3a Oleada del EGM 2017, un total de 2.824.000 oyentes. En Internet, cope.es cuenta con más de 1.700 .000 usuarios únicos según ComScore Octubre 2017, en su cuenta genérica de Twitter, es seguida por más de 300.000 personas y en Facebook, por más de 150.000 .

En un plano analógico, resulta interesante tener en cuenta el perfil del oyente y el del internauta a la hora de elaborar el tipo
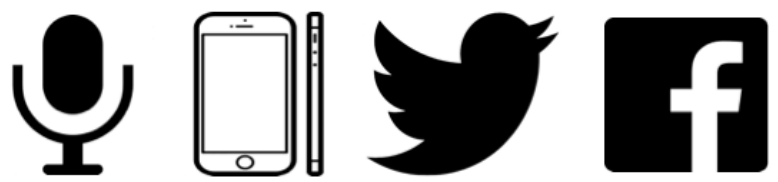

2.824.000 oyentes
Figura 3. Presencia de COPE en plataformas o redes sociales. Cope.es

de información, dado que el contenido de la web viene derivado de la antena. En lo referente a redes y según informes internos de COPE, el $28 \%$ del tráfico de la web procede de este soporte frente al $26 \%$ del tráfico directo o el $42 \%$ de orgánico. Del tráfico social, el 78\% viene de Facebook.

COPE se enfrentaba a una cobertura especial. Tal y como recuerda, el director de Programación, Javier Visiers, "durante

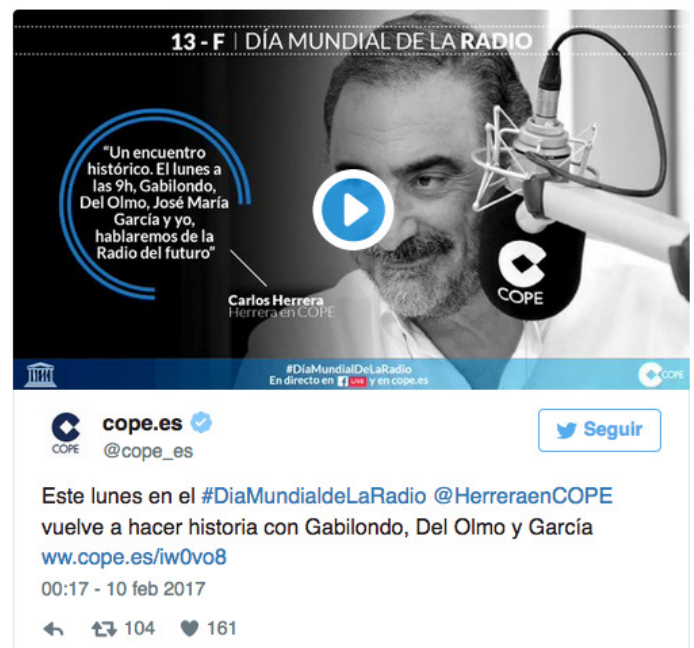

Figura 4. Tweet de COPE con tarjeta sonora. Cope.es semanas habíamos planificado el encuentro de 4 referentes en un día clave". En la antena, se juntarían Carlos Herrera, Luis del Olmo, Iñaki Gabilondo y José María García. Cinco días antes, en la antena con promos y en redes con tarjetas sonoras, COPE anuncia el encuentro.

De ahí que las necesidades que podía cubrir una web como cope.es le llevaran a pensar en su éxito en la medida en que estaban ante un acontecimiento histórico y más aún, ante una gran oportunidad para fidelizar hábitos de consumo y reforzar la marca informativa como grupo y la de COPE en particular.

\begin{tabular}{|l|c|c|}
\hline \multicolumn{1}{|c|}{ Dato } & $06 / 02 / 2017$ & $13 / 02 / 2017$ \\
\hline Sesiones & 110.955 & 139.368 \\
\hline Páginas vistas & 365.086 & 545.819 \\
\hline $\begin{array}{l}\text { Tráfico orgánico (en } \\
\text { número de sesiones) }\end{array}$ & 44.374 & 65.787 \\
\hline Usuarios & 95.805 & 119.838 \\
\hline Usuarios nuevos & 33.790 & 51.874 \\
\hline
\end{tabular}

Tabla 1. Tráfico de cope.es del 6 y 13 de febrero de 2017. Elaboración propia a partir de cope.es
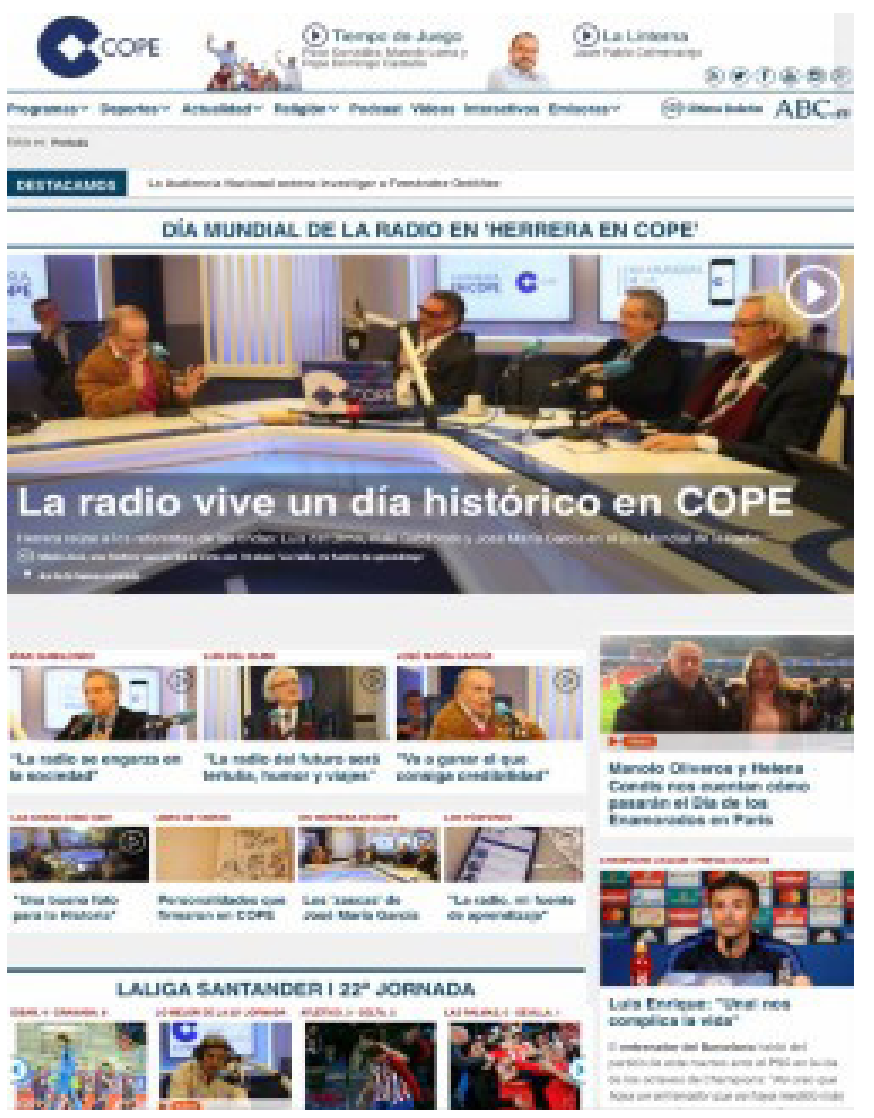

Figura 5. Home de cope.es el 13 de febrero de 2017 


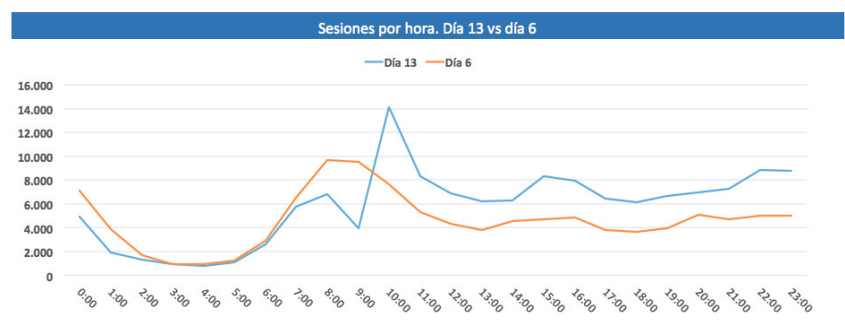

Tabla 2. Sesiones por hora 13 de febrero vs 6 de febrero 2017. Cope.es

A pesar de que la web estuvo caída durante la hora de emisión y de que a lo largo del día el reproductor de audio y vídeo no funcionaba correctamente, aquel 13 de febrero de 2017 los 12 contenidos publicados de la emisión de 'Herrera en COPE' generaron el mayor tráfico de toda su historia con 74.905 páginas vistas. Según COPE, el 44,29\% de los usuarios visitó la noticia principal, el 65,91\% escuchó el audio y el 34,08\% vio el vídeo.

De lunes 13 de febrero a domingo 19, el resultado se eleva a las 120.181 páginas vistas. Es decir, no estando el contenido en la home de COPE, generaba tráfico.

En términos generales, la cita histórica hizo que cope.es superase el medio millón de páginas vistas ese día y creciera hasta un 33\% respecto al lunes anterior. 0 lo que es lo mismo: 180.733 páginas más. El número de usuarios nuevos se vio incrementado hasta un 54\% respecto al 6 de febrero.

En COPE no existía precedente. La emisión especial del Día de la Radio 2017 se empezó a preparar un mes antes. Como apunta Javier Visiers, "trabajan en paralelo el equipo de 'Herrera en COPE', Programación y el área digital. Todos bajo un paraguas de redacción integrada". El monólogo de las 8 se hizo en el estudio $P$ y se retransmitió por Facebook Live, al igual que el tramo de las 9. La web hizo desdoble: emitió el encuentro en audio y vídeo. En cope.es y en Twitter se narró el minuto a minuto con el hashtag \#Los4DeCOPE y \#DiaMundialDeLaRadio. En total, se lanzarón desde la cuenta principal 64 tuits siendo el más destacado la siguiente imagen con 399 'me gusta' y 203 retuits (Figura 6).

Los tuits se emitieron cada 10/15 minutos para recordar la emisión en directo, acompañados del hashtag y como efecto Llamada, una vez finalizada la entrevista. El momento de mayor impacto tuvo lugar de 9:42 a las 9:47h.

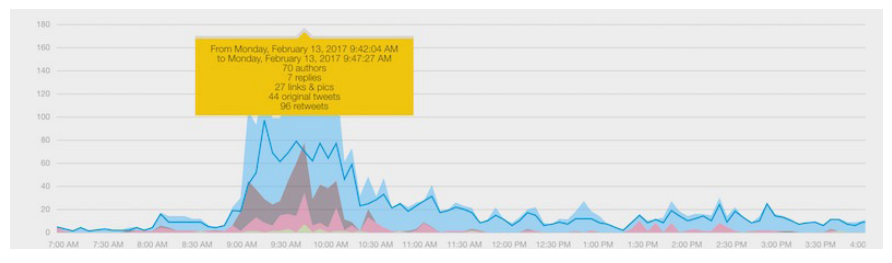

Figura 7. Curva del tráfico de tweets enl 13/02/2017.
8 cope.es $\$$

Día histórico en COPE: @HerreraenCOPE reúne a Gabilondo, Del Olmo y García en el \#DíaMundialdelaRadio \#Los4deCOPE ww.cope.es/j6c6t7

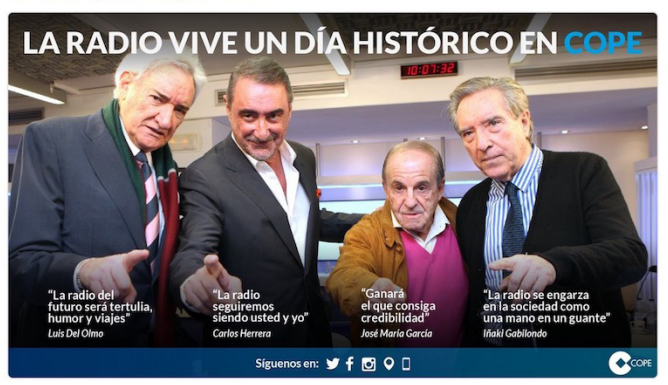

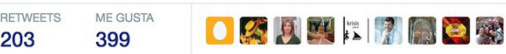

Figura 6. Tweet lanzado desde @cope_es el 13/02/2017.

Además de Twitter, se utilizó Facebook Live de 9 a 10:05h consiguiendo 6.935 personas en directo en tiempo real. Según COPE, casi 2 millones de personas alcanzadas, más de 493.000 reproducciones y más de 3.500 comentarios.

En Facebook la publicación titulada "No te pierdas las imágenes de un \#DíaMundialDeLaRadio histórico con \#Los4deCOPE" fue la de mayor alcance (110.000 personas). Los 64 post fueron acompañados de imágenes.

La noticia más leída en texto/audio fue la titulada: "La radio vive un día histórico en COPE". Tuvo 43.097 páginas vistas en total. El 30,12\% del tráfico fue orgánico, el 26,05\% directo y el

- Cadena COPE $\odot$ transmitió en vivo. Publicado por Emilio AC [?] 13 de febrero a las 10:00 ·

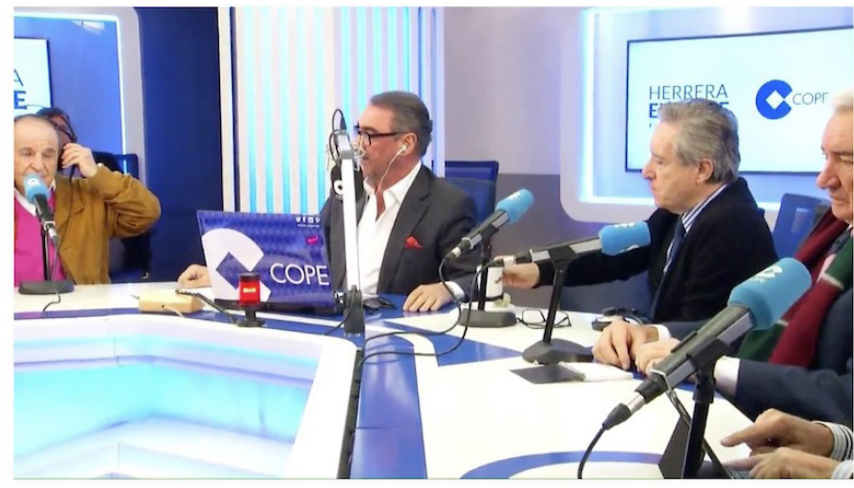

1.917.137 personas alcanzadas

Promocionar publicación

512.225 reproducciones

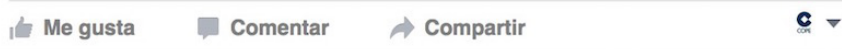
(1) $=9.670$

Comentarios en tiempo real ${ }^{*}$ 3.509 veces compartido 2.865 comentarios

Figura 8. Facebook Live realizado desde la cuenta de COPE el 13/02/2017. 
COPE

Cadena COPE

13 de febrero a las 11:24 C

No te pierdas las imágenes de un \#DíaMundialDeLaRadio histórico con \#Los4deCOPE http://ww.cope.es/wiv2p1

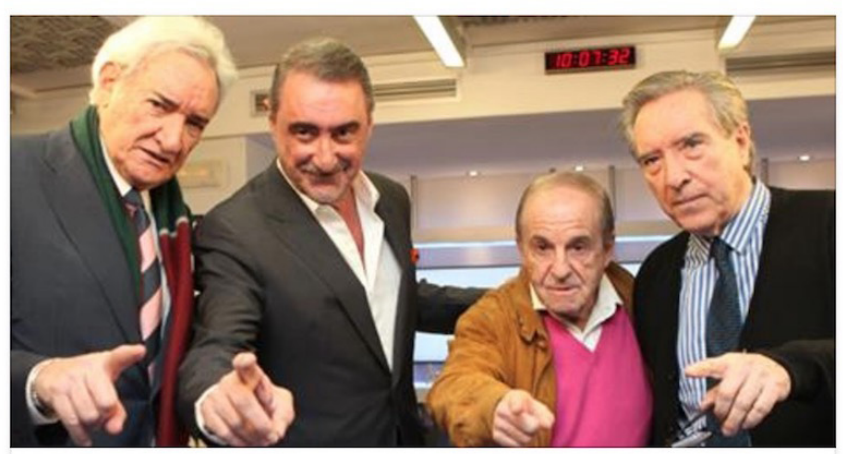

La radio vive un día histórico en COPE | COPE

La Cadena COPE ha celebrado el Día Mundial de la Radio juntando en 'Herrera en COPE' a tres comunicadores históricos de la radiodifusión española: Luis del Olmo, José María Garcá e lñaki Gabilondo. Los tres han contado anécdotas de sus...

WWW.COPE.ES

Figura 9. Post lanzado desde la cuenta de COPE en Facebook el $13 / 02 / 2017$

15,61\% vino de Facebook. Casi la mitad del consumo de esta noticia se hizo por teléfono móvil según COPE. Ninguno de los 12 contenidos publicados llevaba firma.

Por su naturaleza sonora, primó la emisión en directo pero durante la hora que duró el programa la distribución fue triple: lo analógico (transistor), lo digital a través de la web y app y lo digital en redes. Los vídeos generaron 19.041 páginas vistas del total. El 55,12\% del consumo se hizo en Desktop.

Tal y como se ha comentado anteriormente se realizó Facebook Live y se lanzaron alertas a teléfono móvil para redireccionar a la audiencia a la web. En total, 4. Una previa, el domingo a las $21 \mathrm{~h}$ y tres, el día del encuentro (8:51h, 15:09h y 22:22h).

Día histórico en COPE. Herrera reúne a Gabilondo, Del Olmo y García en el Día de la Radio

Figura 10. Alerta enviada por Cope.

\section{Conclusiones}

El estudio de la producción y distribución de contenidos en el caso de 'Herrera en COPE' el Día de la Radio en 2017, permite apuntar, al menos, las siguientes conclusiones:

1. Los días previos a la emisión se establecen los cauces de colaboración necesarios entre los equipos (Herrera en COPE y cope.es) pero durante el programa no hay comunicación. La producción de los 12 contenidos recae exclusivamente en el área digital.
2. Cada soporte tiene su lenguaje y su ritmo de producción. Durante la emisión del programa y en las horas posteriores, la figura del Chief Editor Digital de COPE resulta imprescindible para determinar en qué formato va cada uno de los 12 contenidos creados, cuándo y dónde se publican.

3. El carácter inmediato de las plataformas analizadas (antena, web y teléfono movil/redes) condiciona el trabajo de los equipos encargados de producir y distribuir contenidos.

4. La promoción cruzada de la marca COPE a través de la antena, la web, la app y las redes durante los días previos y el 13 de febrero, generó una fidelización del público. El número de usuarios concurrentes aumentó un 8\% y el de nuevos un $65 \%$. Es el tránsito de la economia de la atención a la economia de la confianza.

\section{Referencias}

Armentia-Vizuete, J. I.,Caminos-Marcet, J. M., y Elexgaray-Arias, J. (2000). El Diario Digital. Análisis de los contenidos textuales, aspectos formales y publicitarios. Barcelona: Bosch.

Bruhn-Jensen, K (1993). Introducción: el cambio cualitativo. En: Metodologías cualitativas de investigación en comunicación de masas (pp. 9-20). Barcelona: Bosch.

Cabrera, M. (2012). ¿Qué son los nuevos medios y lo medios sociales? Madrid: Fundeu BBVA. Recuperado de https://www.fundeu.es/escribireninternet/que-son-los-nuevos-medios-y-los-medios-sociales

Castells, M., Fernández-Ardèvol, M., Linchuan-Q̣iu, J., y Sey, A. (2006). Comunicación móvil y sociedad. Una perspectiva global. Barcelona: Ariel-Fundación Telefónica.

Cebrián Herreros, M. (2008). La radio en internet. De la ciberradio a las redes sociales y la radio móvil. Buenos Aires: La Crujía.

Cerezo, P. (2016). Los customer media. Medios líquidos para usuarios hiperconectados. Madrid: Evoca. Recuperado de http://www.amic. media/media/files/file_352_1027.pdf

Chávez, I. (2013). Radio universitaria y podcasting. Análisis de los modelos de Podcasting utilizados en Internet por emisoras universitarias de España y México. (Tesis doctoral). Sevilla: Universidad Internacional de Andalucía.

De Biase, L. (2011). Cambiare de pagina: per sopravvivere ai media della solitudine. Milan: Rizzoli.

Fogel, J. F., y Patiño, B. (2007). La prensa sin Gutenberg. El periodismo en la era digital. Madrid: Punto de Lectura.

García-Avilés, J. A. (2002). Periodismo polivalente y convergente: riesgos y oportunidades para el periodismo audiovisual. Chasqui. Revista Latinoamericana de comunicación, (79),38-43.

Goldhaber, M. H. (1997). The Attention Economy and the Net. First Monday, 2(4). Recuperado de http://firstmonday.org/ojs/index.php/ $\mathrm{fm} /$ article/view/519/440

Hermida, A. (2010). Twittering the news: The emergence of ambient journalism. Journalism practice, 4(3), 297-308. 
IAB Spain (2017). Estudio anual de Redes Sociales. 2017, Madrid: IAB. Recuperado de http://www.iabspain.net/wp-content/uploads/ downloads/2014/04/V-Estudio-Anual-de-Redes-Sociales-versi\%C3\%B3n-reducida.pdf

Jenkins, H. (2008). Convergence Culture. La cultura de la convergencia de los medios de comunicación. Barcelona: Paidós.

López X., y Pereira, X. (Coord.). (2010). Convergencia digital. Reconfiguración de los medios de configuración en España. Santiago de Compostela: Universidad Santiago de Compostela.

Merayo, A. (2001). Formación, nuevos contenidos y creatividad sonora: apuestas para un tiempo de incertidumbre tecnológica. En: Martínez-Costa, María del Pilar (Coord.), Reinventar la radio. Actas de las XV Jornadas Internacionales de la Comunicación. Universidad de Navarra. (pp. 281-291) Pamplona. España: Ed. Eunate.

Meso, K. (2013), Periodismo y audiencias: inquietudes sobre los contenidos generados por los usuarios. Cuadernos, (33), 63-73.

Nieto, A.(2001). Economía de la apariencia y mercado de la información. Comunicación y Sociedad, 14(2), 117-142.

Orihuela, J. L. (2003). Los weblogs ante los paradigmas de la e-Comunicación: 10 principios del nuevo escenario mediático. $V$ Foro de Investigación Europea en Comunicación: La comunicación. Nuevos discursos y perspectivas. Madrid.

Peñafiel, C. (2001). La informatización en las redacciones de radio: un camino sin retorno. Reinventar la Radio, Actas de las XV Jornadas Internacionales de la Comunicación, (pp. 65-69). Pamplona: Eunate.

Peñafiel, C. (2004). La cara i la creu de la ràdio digital a Espanya. Quaderns del CAC, (18), 13-32.

Piñeiro-Otero, T., y Videla, J. J. (2013). La participación de los oyentes en las radio APPs españolas. Prácticas convencionales en la era de la portabilidad. adComunica, (5), pp.67-89.

Rivadeneyra, C. (2008). Pugna, convergencia y diversidad de la radio latinoamericana en el escenario digital. En: Ortega Carmona, Leopoldo (Coord.), Memorias de la $7 a$ Bienal Internacional de Radio México. Colonia del Valle: Radio Educación.

Salaverría, R. (2002).¿Hacia dónde se dirige la convergencia de medios? Conferencia en el Seminario "Beyond the Printed Word", IFRA/WAN/FIPP World Electronic Publishing Conference. Barcelona.
Simon, H. (1971). Designing Organizations for a Information-rich World. En: Greenberger, M. (ed.), Computers, Communications and the Public Interest, Baltimore: The Johns Hopkins Press.

Tous-Rovirosa, A., Rivero-Santamarina, D., Meso, K., y Larrondo, A. (2015). Ambient Journalism in Spain. How Twitter and NREs are Redefining Agenda Setting in El País, El Mundo, La Razón, ABC and La Vanguardia". Trípodos. (36), pp 35-54.

Wimmer, R., y Dominick, J. (1996). La investigación científica de los medios de comunicación. Una introducción a sus métodos. Barcelona: Bosch Comunicación.

\section{CV}

Andoni Orrantia. Es profesor titular de Información en radio en el Centro Universitario Villanueva (Madrid) y de La radio en la convergencia digital multimedia en el Máster de Radio de CEU San Pablo-COPE. Es Máster en Comunicación Social(UPV-EHU), licenciado en Comunicación Audiovisual por la Universidad de Navarra (UN) y posee estudios en Derecho por la UNED. En radio ha trabajado en los Servicios Informativos de la Cadena SER, en Onda Cero, Radio Euskadi, Sinfo Radio Antena3, Vatican Radio (Italia) y en COPE donde en la actualidad asume las funciones de subdirector de Programación y Chief Digital Officer. En televisión, ha trabajado en Telecinco y en ETB. También ha escrito en cabeceras como El País, Deia, Diario de Navarra y eldiario.es. Vinculado al mundo académico, ha impartido clases en la Facultad de Comunicación de la Universidad de Navarra (UN). Actualmente es profesor en el Grado de Periodismo en el Centro Universitario Villanueva y en el Máster Multimedia de Radio COPE-San Pablo CEU. Andoni Orrantia ha participado en decenas de congresos de Periodismo. Además, como consultor de comunicación ha redactado numerosos Planes Estratégicos para empresas privadas y también asesora a medios de comunicación. Es autor de los ensayos Y de repente, no había plan B. De la desafección política a la mediática (2015) y ¿Qué es notici@? O cómo distinguir lo interesante de lo importante (2014).

\section{осм Observatorio de Cibermedios}

\author{
https://observatoriocibermedios.upf.edu/

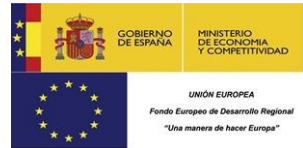

El Observatorio de Cibermedios es una producción del Grupo de Investigación en Documentación Digital y Comunicación Interactiva (DigiDoc) del Departamento de Comunicación de la Universitat Pompeu Fabra.

El Observatorio de Cibermedios (OCM) forma parte del proyecto del Plan Nacional "Creación y contenido interactivo en la comunicación de información audiovisual: audiencias, diseño, sistemas y formatos". CS02015-64955-C4-2-R (MINECO/ FEDER), Ministerio de Economía y Competitividad (España). 